\title{
Altered conscious state as a presentation of the syndrome of transient Headache and Neurological Deficits with CSF Lymphocytosis (HaNDL syndrome) in a paediatric patient
}

\author{
INSTRUCTIVE CASE
}

Authors: Dr Raffaela Armiento ${ }^{1}, \mathrm{~A} /$ Prof Andrew J Kornberg $^{2}$

Departments of ${ }^{1}$ General Paediatrics and ${ }^{2}$ Neurology, Royal Children's Hospital, Parkville, 3052

Address: Royal Children's Hospital, 50 Flemington Rd Parkville, 3052

Corresponding author details:

- Raffaela Armiento

- Junior Medical Staff, Royal Children's Hospital, 50 Flemington Rd Parkville, 3052.

- Email; raff.armiento@gmail.com

- Ph: 0421527022
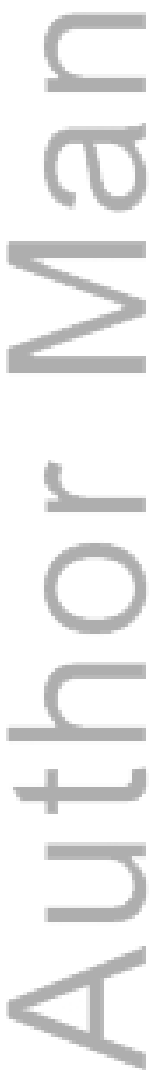

This is the author manuscript accepted for publication and has undergone full peer review but has not been through the copyediting, typesetting, pagination and proofreading process, which may lead to differences between this version and the Version of Record. Please cite this article as doi: 10.1111/jpc.13199

This article is protected by copyright. All rights reserved. 


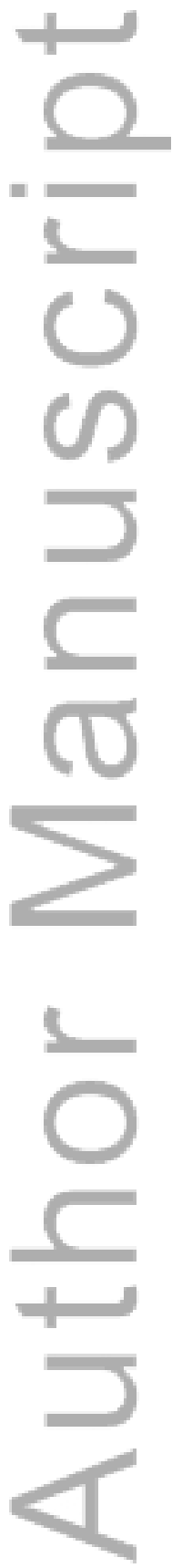

This article is protected by copyright. All rights reserved. 


\section{MAIN TEXT}

\section{Abstract and Key Words}

We describe the case of a previously well 12-year-old who presented with headache and rapidly progressive altered conscious state. After a period of intensive care support, she had rapid and complete resolution of her symptoms and HaNDL syndrome was diagnosed. HaNDL syndrome (the syndrome of transient Headache and Neurological Deficits with CSF Lymphocytosis) is a rare, benign and self-limiting condition. It is an important clinical entity to recognise as a diagnosis of exclusion.

Key words: HaNDL, Headache, Altered conscious state, Neurology

\section{Text}

Case Report

A previously healthy 12-year-old girl with a history of headaches presented with altered conscious state. She had had an upper respiratory tract infection 2 weeks prior to presentation. Onset was with 2 days of throbbing headache associated with blurred vision and vomiting. There was no associated fever and no infective features. On the day of presentation she reported a worsening headache and later became acutely confused, combative, had slurred speech and weakness which evolved over 12hrs. Her Glasgow Coma Scale (GCS) was 9 on arrival, and there was lower limb hypotonia and hyporeflexia. Plantar reflexes were equivocal and the remainder of her examination was normal. There was no evidence of meningeal irritation. Her conscious state deteriorated further and she was therefore intubated for airway protection. She received empiric IV Ceftriaxone and Aciclovir, as well as Dexamethasone for possible encephalitis.

CT brain was normal. MRI brain did not reveal any abnormalities on T1 or T2 weighted images, pre or post contrast images, diffusion weighted images or FLAIR images. MRI spine was also normal. Analysis of the cerebrospinal fluid (CSF) taken $24 \mathrm{hrs}$ after presentation revealed a lymphocytosis $48 \times 10^{6} / \mathrm{L}, 0$ polymorphs and a few red blood cells $3 \times 10^{6} / \mathrm{L}$. Protein was normal at $0.23 \mathrm{~g} / \mathrm{L}(0.2-0.4)$ and glucose slightly raised at $4.2 \mathrm{mmol} / \mathrm{L}(0.2-0.4)$. An opening pressure was not obtained. CSF microbiological and virologic analyses including PCR for Enterovirus, Herpes Simplex Virus I and Adenovirus were negative. Normal investigations included liver function tests, electrolytes and renal function, thyroid function, ammonia, urine metabolic screen, creatine kinase, serum paracetamol level, blood and urine culture and viral PCR on nasopharyngeal aspirate. Other relevant investigations are listed in Table 1.

The patient was extubated after $24 \mathrm{hrs}$ and had a normal neurological examination thereafter. Aciclovir and Ceftriaxone were discontinued once CSF virology and microscopy, culture and sensitivity (MCS) were negative.

The patient had no further neurological events in the 4 months following the initial episode. A diagnosis of HANDL was made. 


\section{Discussion}

In the setting of headache and neurological dysfunction with aseptic CSF lymphocytosis and normal brain imaging, this patient fulfilled criteria for the syndrome of transient Headache and Neurological Deficits with CSF Lymphocytosis (HaNDL).

HaNDL syndrome is a rare, benign, self-limiting condition characterised by one or more episodes of transient neurological deficits associated with headache and CSF lymphocytosis ${ }^{1}$. Significant lymphocytosis is defined as $>15 \times 10^{6} / \mathrm{L}^{1}$. It was first described in 1981 and in 1995 Berg and Williams established the name HaNDL and provided diagnostic criteria ${ }^{2-3}$. Current diagnostic criteria are shown in Table 2. HaNDL syndrome has also been known as pseudomigraine with temporary neurological symptoms and lymphocytic pleocytosis, and as a migrainous syndrome with pleocytosis ${ }^{1}$.

HaNDL is most commonly diagnosed in the third or fourth decades of life and is rare in the paediatric population ${ }^{4}$. Only 16 paediatric cases have previously been published ${ }^{4-6}$. A combative or altered conscious state is a rare neurological feature of HaNDL and only 9 cases have been reported, of which 1 was a paediatric patient ${ }^{5,7}$.

Clinical presentation of HaNDL is with one to $>20$ episodes of moderate to severe headache associated with neurological deficits ${ }^{1}$. Neurological manifestations include sensory symptoms (78\% of cases), aphasia (66\%), motor deficits (56\%) and less commonly aura-like visual disturbances $(18 \%)^{1}$. There is a close temporal relationship between headache and neurological symptoms, which may occur before, during or after the onset of headache ${ }^{8}$. A viral infection precedes one third of cases, suggesting a possible aetiological link ${ }^{5}$. Symptoms usually resolve over hours but may persist for up to 3 days $^{1,8}$. Episodes may be isolated or if they recur, will do so in the first 3 months after the initial attack $^{1}$. Patients are asymptomatic between events ${ }^{1}$. Thereafter, there are no further episodes and no neurological sequelae ${ }^{8}$.

HaNDL is a diagnosis of exclusion, with the differential diagnoses including severe and life threatening conditions $^{1}$. A leucocytosis may be present, though other blood tests are unremarkable ${ }^{8}$. There may be a raised opening pressure on CSF sampling $(10-40 \mathrm{~cm} \mathrm{H} 20)^{1}$. CSF shows a lymphocytosis (10760 cells $/ \mathrm{ml})$ and there is a high protein level in $>90 \%(20-250 \mathrm{mg} / \mathrm{dl})$ with normal glucose and no oligoclonal bands. CSF culture and infective PCRs are negative. CSF lymphocytosis resolves over time, though the duration is unknown ${ }^{4}$. Routine CT and MRI brain must be normal ${ }^{1}$. Cerebral angiography is also normal ${ }^{8}$. Brain Single Photon Emission CT may show focal hypoperfusion in areas consistent with the clinical symptoms ${ }^{6}$. EEG shows focal slowing in the affected hemisphere, which is transient ${ }^{5}$.

The pathophysiology of HaNDL syndrome is unknown ${ }^{4}$. There are three major hypotheses; firstly that it is a form of atypical migraine, though the duration of symptoms is longer than most migraines and the neurological features differ from a typical aura ${ }^{8}$. Most patients have no prior or family history of migraine ${ }^{1}$. Second is the suggestion of a meningoencephalopathy, though infective features are not present in all cases, and meningitic signs are absent ${ }^{8}$. The current leading hypothesis is neuronal spreading depression, likely triggered by viral infection, which triggers sterile inflammation ${ }^{8}$.

Once diagnosed, management of HaNDL syndrome consists of symptomatic headache management ${ }^{4}$. Particularly given the potential for recurrent episodes within the first 3 months, education and reassurance of the patient and family is paramount ${ }^{4}$.

This case highlights that HaNDL must be considered alongside more common differential diagnoses, even in the paediatric population, as a diagnosis of exclusion. Altered conscious state is a rare manifestation of HaNDL and this is the $2^{\text {nd }}$ reported paediatric case ${ }^{5}$. Recognition of this diagnosis may prevent recurrent investigations that may be invasive or costly ${ }^{4}$. 


\section{Multiple Choice Questions}

1. Which of the following is NOT a diagnostic criterion for HaNDL syndrome

a. Normal neuroimaging

b. CSF lymphocytosis

c. Ongoing neurological deficits $>3$ months

d. Episodes fully resolve

e. Close temporal relationship between headache and neurological abnormalities

2. Which of the following is the most common neurological symptom

a. Sensory symptoms

b. Motor deficits

c. Altered conscious state

d. Visual disturbances

e. Aphasia

3. Which of the following investigations is NOT an associated feature of HaNDL syndrome?

a. Focal slowing on EEG

b. Raised CSF opening pressure

c. Raised CSF protein

d. Thrombocytopaenia

e. Normal cerebral angiography

MCQ Answers

1. $\mathrm{c}$

2. a

3. $d$

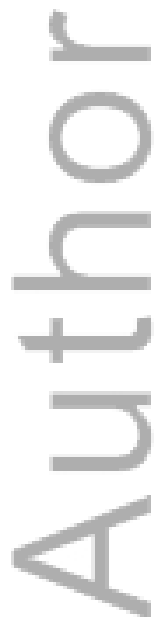

This article is protected by copyright. All rights reserved. 


\section{References}

1. International Headache Society (UK). Syndrome of transient Headache and Neurological Deficits with Cerebrospinal Fluid Lymphocytosis (HANDL) [Internet]. International Classification of Headache Disorders - II (UK); [cited 2015 Dec 10]. Available from: http://ihs-classification.org/en/02_klassifikation/03_teil2/07.08.00_nonvascular.html

2. Bartleson JD, Swanson JW, Whisnant JP. A migrainous syndrome with cerebrospinal fluid pleocytosis. Neurology. 1981 Oct;31(10):1257-62.

3. Berg MJ, Williams LS. The transient syndrome of headache with neurologic deficits and CSF lymphocytosis. Neurology. 1995 Sep;45(9):1648-54.

4. Gonçalves D, Meireles J, Rocha R, Sampaio M, Leão M. Syndrome of transient headache and neurologic deficits with cerebrospinal fluid lymphocytosis (HaNDL): a pediatric case report. J Child Neurol. 2013 Dec;28(12):1661-3.

5. Soto-Insuga V, López-Villanueva L, Rodrigo M, Mois Aroyo I, Losada R, Soriano-Guillén L. Confusion as a presentation symptom of pseudomigraine with pleocytosis in a paediatric patient. An Pediatr (Barc). 2014 Jun;80(6):394-8.

6. Filina T, Feja KN, Tolan RW Jr. An adolescent with pseudomigraine, transient headache, neurological deficits, and lymphocytic pleocytosis (HaNDL Syndrome): case report and review of the literature. Clin Pediatr (Phila). 2013 Jun;52(6):496-502.

7. Lo Re M, di Sapio A, Malentacchi M, Granieri L, Bertolotto A. Acute confusional state in HaNDL syndrome (transient headache and neurologic deficits with cerebrospinal fluid lymphocytosis). Neurol Sci. 2015 Mar;36(3):477-8.

8. Cifelli A, Vaithianathar L. Syndrome of transient Headache and Neurological Deficits with cerebrospinal fluid Lymphocytosis (HaNDL). BMJ Case Rep. 2011 Mar 29;2011.
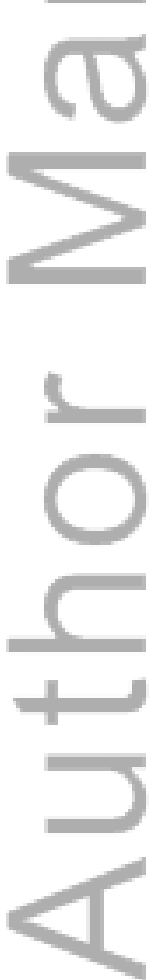
Tables

\begin{tabular}{|l|l|}
\hline \multicolumn{2}{|l|}{ Table 1: Investigations } \\
\hline Test & Result \\
\hline Full Blood Examination & Mild neutrophilia $10.82\left(1.8-8.0 \times 10^{9} / \mathrm{L}\right)$ \\
\hline C-Reactive Protein & $<0.7 \mathrm{mg} / \mathrm{L}(<0.7)$ \\
\hline Procalcitonin & $<0.06 \mathrm{ug} / \mathrm{L}(<0.06)$ \\
\hline Venous Blood Gas & Mild respiratory acidosis; $\mathrm{pH} 7.3, \mathrm{pCO} 250, \mathrm{HCO} 25, \mathrm{BE}-2.4$, Glucose \\
& 5.5 \\
\hline Urinary drug screen & Positive for Benzodiazepines and Opiates (after sedation) \\
\hline Urine microscopy & 0 leucocytes, 0 erythrocytes, no growth \\
\hline
\end{tabular}

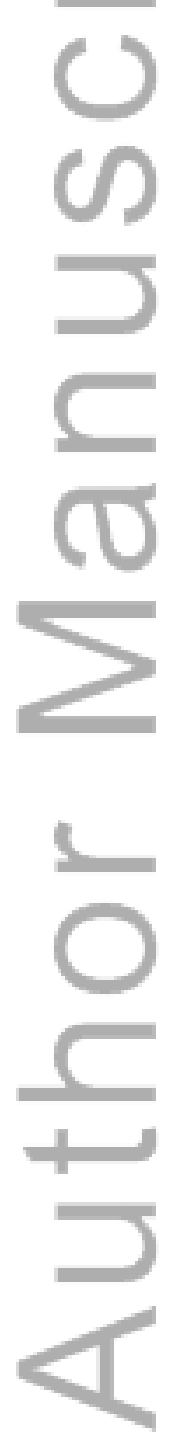

This article is protected by copyright. All rights reserved. 


\begin{tabular}{|l|l|}
\hline \multicolumn{2}{|l|}{ Table 2: International Headache Society (IHS) Diagnostic Criteria for HaNDL Syndrome ${ }^{1}$} \\
\hline A & $\begin{array}{l}\text { Episodes of moderate or severe headache lasting hours before fully resolving and fulfilling } \\
\text { criteria C and D }\end{array}$ \\
\hline B & $\begin{array}{l}\text { Cerebrospinal fluid pleocytosis with lymphocytic predominance (15cells/ul) and normal } \\
\text { neuroimaging, CSF culture and other tests for aetiology. }\end{array}$ \\
\hline C & $\begin{array}{l}\text { Episodes of headache are accompanied by or shortly follow transient neurological deficits and } \\
\text { commence in close temporal relation to the development of CSF pleocytosis }\end{array}$ \\
\hline D & Episodes of headache and neurological deficits recur over <3months \\
\hline
\end{tabular}

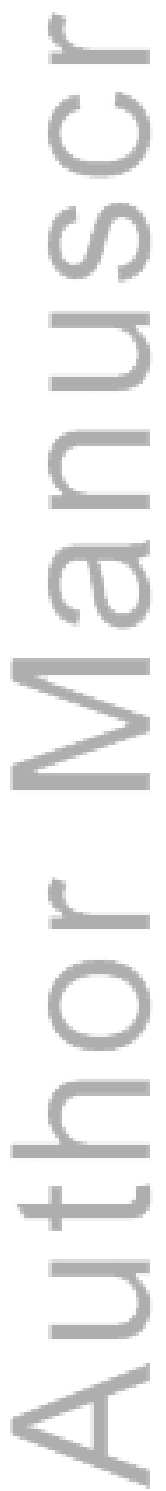

This article is protected by copyright. All rights reserved. 
Key Points

1. HaNDL is a rare syndrome of transient neurological deficits accompanied by headache

2. HaNDL is a diagnosis of exclusion and may mimic severe or life threatening conditions

3. Altered conscious state is a rare manifestation of HaNDL
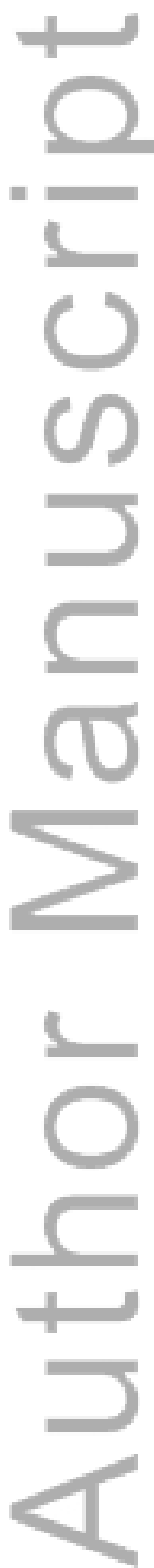

This article is protected by copyright. All rights reserved. 


\section{University Library}

\section{- M I I N E R VA \\ A gateway to Melbourne's research publications}

Minerva Access is the Institutional Repository of The University of Melbourne

Author/s:

Armiento, R;Kornberg, AJ

Title:

Altered conscious state as a presentation of the syndrome of transient headache and neurological deficits with cerebrospinal fluid lymphocytosis (HaNDL syndrome) in a paediatric patient

Date:

2016-07-01

Citation:

Armiento, R. \& Kornberg, A. J. (2016). Altered conscious state as a presentation of the syndrome of transient headache and neurological deficits with cerebrospinal fluid lymphocytosis (HaNDL syndrome) in a paediatric patient. JOURNAL OF PAEDIATRICS AND CHILD HEALTH, 52 (7), pp.774-776. https://doi.org/10.1111/jpc. 13199.

Persistent Link:

http://hdl.handle.net/11343/291373 